\title{
As METÁforas do PRESIDENTE LULA NA PERSPECTIVA DA Linguística de Corpus: O Caso do desenvolvimento
}

(President Lula's metaphors in a corpus linguistic perspective: The case of 'development')

Tony Berber SARdinha

$(P U C-S P)$

Resumo: Um dos grandes fenômenos linguísticos da vida política brasileira recente é o que a mídia vem chamando de 'metáforas do presidente Lula'. O ponto de partida deste trabalho é o fato de que deve haver muitas metáforas que passam despercebidas no discurso do presidente e que podem ser descobertas por meio de pesquisa com corpora eletrônicos. Investigamos a presença de metáforas conceptuais relacionadas a 'desenvolvimento' em um corpus composto por pronunciamentos emitidos ao longo de três anos pelo presidente Luís Inácio Lula da Silva. Os resultados indicam que há uso sistemático de três conceitos metafóricos que definem a noção de desenvolvimento do chefe de Estado: VIAGEM, CONSTRUÇÃo e ORGANISMO. Esses três conceitos, em geral, equacionam desenvolvimento com um processo longo, construído, planejado e gerado pelo governo.

Palavras-chave: metáfora; Linguística de Corpus; presidente Lula; WordSmith Tools.

Abstract: One of the main linguistic phenomena in recent Brazilian politics is what the media has called 'President Lula's metaphors'. The starting point for the present investigation is that there must be lots of metaphors that go unnoticed in the president's discourse and that these may be uncovered by corpus-based research. We looked at the presence of conceptual metaphors related to 'development' in a corpus of three years of official presidential speeches. The results indicated the systematic use of three metaphorical concepts that together define the notion of development for the head of State: JOURNEY, BUILDING and ORGANISM. These three concepts together equate development with a long process that is generated, planned and carried out by the government.

Key-words: metaphor; Corpus Linguistics; President Lula; WordSmith Tools.

\section{INTRODUÇ̃̃O}

Um dos grandes fenômenos linguísticos da vida política brasileira recente é o que a mídia vem chamando de 'metáforas do presidente Lula'. 
Desde que os jornais e revistas perceberam que Luís Inácio Lula da Silva emprega deliberadamente metáforas em seus discursos e pronunciamentos, houve comentários incessantes sobre a eficácia de tal recurso na sua argumentação. Lendo tais matérias, percebe-se que metáfora, para os analistas da fala do presidente, é um recurso de retórica para tornar as ideias mais claras para a audiência e convencer a plateia. À medida que as metáforas 'tornam mais fácil' a compreensão de temas complexos (como a política monetária) para uma população em grande parte iletrada, elas ainda ajudam a 'guiar' a compreensão do interlocutor para um desfecho desejado. Por exemplo, quando Lula explica a situação econômica grave em que encontrou o país dizendo que 'o Brasil estava numa UTI', ele torna mais concreto e palpável o sentido abstrato de 'déficit federal orçamentário' e guia a compreensão dessa situação em termos de um doente internado em UTI.

Esse foi apenas um dos exemplos de metáfora do presidente Lula, notadamente um daqueles que saltam aos olhos. O ponto de partida deste trabalho, contudo, é o fato de que deve haver muitas outras metáforas que passam despercebidas no discurso do presidente e que podem ser descobertas por meio de pesquisa com corpora eletrônicos (Charteris-Black, 2004; Deignan, 2005). Corpora são coletâneas de textos ou transcrições de fala armazenadas em formato de computador utilizadas para pesquisa linguística (Berber Sardinha, 2004, 2005). A área dos estudos linguísticos que se ocupa da coleta e exploração de corpora é a Linguística de Corpus. Neste trabalho propomos uma investigação acerca de metáforas empregadas no discurso do presidente Luís Inácio Lula da Silva por meio da Linguística de Corpus.

\section{Metáfora}

A palavra 'metáfora' tem origem no grego 'metapherein', que significa 'transferência' ou 'transporte'. Etimologicamente, é formada por 'meta', que quer dizer 'mudança' e por 'pherein' que significa 'carregar'.

Tradicionalmente, a metáfora é vista como recurso figurativo, isto é, como uma maneira para ornamentar, embelezar a linguagem. Entretanto, essa visão de metáfora não consegue lidar com o uso da metáfora no quotidiano, em situações nas quais a metáfora é empregada para agir e interagir no mundo. 
Há muitas teorias e abordagens de metáfora atualmente em circulação (Berber Sardinha, 2007); dentre elas, para os propósitos deste trabalho, podemos destacar duas: a da Metáfora Discursiva (Cameron, 2003) e a da Metáfora Conceptual (Lakoff \& Johnson, 1980).

A teoria da Metáfora Discursiva tem como ênfase o estudo da metáfora em uso, no discurso. Ela está sendo desenvolvida por um grupo liderado por Lynne Cameron e tem como finalidade entender como e por que as pessoas empregam metáforas e que efeito as metáforas têm na interação. Isso é feito buscando-se sistematicidades do uso metafórico em textos e falas autênticas, colhidos em contexto real de produção. A unidade de análise primordial dessa corrente é a metáfora linguística, que pode ser vista como um trecho de texto falado ou escrito cujo significado no contexto é diferente de seu sentido base (basic sense) e que se remete a um domínio ou campo semântico diferente do predominante no discurso naquele momento. Essa perspectiva vê a metáfora de vários ângulos, conforme explica Cameron (2007: 200):

Metaphor is seen as linguistic, cognitive, affective and socio-cultural. Metaphor is linguistic in that the primary data available to discourse analysts are metaphors in the utterances of discourse participants (...). It is cognitive in that individual instances of metaphor may reflect larger conceptual metaphorical structures in which larger domains are mapped on to each other. It is affective in that (...) [metaphors] are evaluative, emphatic or act to position speakers relative to other people or to the content of which they talk. Metaphor is socio-cultural as well as cognitive because social interaction is the site of metaphor use and evolution, and because social groups develop particular metaphorical ways of thinking, together with ways of using metaphor in language, that may act as markers or constructors of social and role identity.

Dessa abordagem, tomamos os conceitos de Tópico e Veículo. Veículo é o elemento linguístico que sinaliza a metáfora linguística. Por exemplo, em 'nosso noivado está a todo vapor', '(está) a todo vapor' é o Veículo; 'nosso noivado' é o Tópico. O Tópico é também metaforizado pela presença do Veículo; no exemplo anterior, 'nosso noivado' é metaforizado como uma máquina de transporte (um trem puxado por uma locomotiva veloz ou algo assim) que está desenvolvendo alta velocidade. Ele pode ainda estar ausente ou implícito na metáfora linguística. Em uma conversa onde se discuta o noivado de um dos interlocutores, seria perfeitamente compreensível o uso de 'a todo vapor' sozinho num enunciado para se referir a noivado. 
Já na Teoria da Metáfora Conceptual, a metáfora é vista fundamentalmente como um tipo de processamento mental. Esse processamento é o que nos permite entender conceitos abstratos como amor, tempo e vida, entre outros. Por exemplo, quando dizemos 'meu casamento está indo de vento em popa', estamos conceitualizando amor em termos de uma viagem. Partimos de um conceito concreto, a viagem, para entender um conceito abstrato, o amor. Daí chegamos à metáfora conceptual AMOR É UMA VIAGEM. A metáfora está nessa relação entre dois conceitos díspares que se unem para que possamos entender um deles em termos do outro. Assim, os casais se metaforizam em viajantes, a vida conjugal se metaforiza numa jornada e as brigas se metaforizam em acidentes de percurso.

Um conceito central na Teoria da Metáfora Conceptual é o de Domínio, que são esferas de conhecimento ou de atuação humana que entram em jogo numa metáfora conceptual. No exemplo da metáfora AMOR É UMA viagem, visto acima, há dois Domínios: amor e viagem. Amor é chamado de Domínio Alvo ('target domain'), pois ele é o Domínio metaforizado; viagem, por sua vez, é o Domínio Fonte ('source domain'), pois é dele que emprestamos os elementos para metaforizar o outro Domínio. As relações entre os elementos de um Domínio e de outro são chamadas de Mapeamentos ('mappings').

As metáforas conceituais são, nessa visão, maneiras de que nossa mente dispõe para lidar com a vida ao nosso redor, o nosso cotidiano. As metáforas passam a ser recursos corriqueiros, que qualquer um coloca em prática, independente de seu nível de instrução. Qualquer um pode dizer 'meu namoro não vai bem', sem se dar conta que está metaforizando o conceito de amor, pois o conceito de amor é naturalmente metafórico. Não há maneiras 100\% literais de expressar o conceito de amor. Podemos tentar definir amor de maneira puramente biológica, como alguns tentam fazer, dizendo que se trata de uma reação química impulsionada pelo instinto de procriação. Mas essa definição deixa de lado a essência do amor, o sentimento, as emoções, sendo, portanto, insatisfatória para exprimir esse conceito na sua plenitude e no nível em que as pessoas o percebem no dia a dia. Além disso, mesmo que desçamos a esse nível 'básico' dos processos biológicos do organismo para definir amor, logo nos depararemos com algumas metáforas! Por exemplo, se dissermos que os 'neurônios de um amante enviam informações para os músculos e os órgãos', estaremos empregando pelo menos uma metáfora nessa explicação: 'enviar informação'. Claramente, os neurônios 
não enviam informação de fato. Eles enviam correntes elétricas e substâncias químicas que interpretamos como informação; ou seja, já metaforizamos a troca de impulsos elétricos entre células como 'informação'. Dessa forma, atribuímos sentido a essa troca.

Esse exemplo ilustra o fato de que a metáfora é essencialmente um processo de construção de sentido do mundo ao nosso redor. Atribuímos sentido às coisas à nossa volta para que possamos ver sentido nelas. Assim, quando o computador não funciona, dizemos que 'ele não quer cooperar' e dessa forma o metaforizamos em uma pessoa. Quando temos pressa, dizemos 'tempo é dinheiro', e assim metaforizamos a perda de tempo em perda de dinheiro, algo palpável. Quando conseguimos um emprego melhor, dizemos que 'subimos na vida', metaforizando a melhora financeira em uma posição espacial (para cima).

Os exemplos acima expõem os dois tipos chave de metáfora de que estamos tratando: a conceptual e a linguística. A metáfora conceptual, conforme dissemos, exprime um conceito que surge a partir da aproximação de dois conceitos díspares. A metáfora linguística, por sua vez, são as palavras realmente empregadas no texto e na fala de modo metafórico. $\mathrm{Na}$ Teoria da Metáfora Conceptual, dizemos que a metáfora conceptual subjaz à metáfora linguística; ou seja, a metáfora conceptual não é verbalizada, ela reside na mente dos falantes e 'licencia' as metáforas linguísticas. Esse licenciamento é o responsável pela inteligibilidade de várias metáforas linguísticas numa dada cultura. Por exemplo, 'nosso noivado está a todo vapor', 'nosso casamento naufragou' e 'estamos indo de vento em popa' são todas metáforas linguísticas licenciadas pela metáfora conceptual AMOR É UMA VIAGEM. Na nossa cultura brasileira, ocidental, não estranhamos tais expressões quando as empregamos para falar de casamento, vida conjugal, relacionamento marido e mulher e coisas assim relacionadas ao amor. $\mathrm{Ou}$ seja, no contexto de amor, tais expressões são interpretáveis naturalmente, em nossa cultura, com referência ao amor, devido ao licenciamento providenciado pela metáfora conceptual que os falantes possuem internalizada. $\mathrm{Na}$ abordagem da Metáfora Discursiva, dizemos que a metáfora linguística é a unidade primordial de análise e que não temos como saber se a mente das pessoas processou metáforas conceptuais de verdade. Por isso, devemos nos ater apenas às metáforas linguísticas.

Nossa posição neste trabalho é que precisamos das duas abordagens. Da Metáfora Discursiva tomamos a noção de metáfora linguística e os con- 
ceitos de Tópico e Veículo para operacionalizar a análise das metáforas no contexto. Da Metáfora Conceptual tomamos a própria noção de metáfora conceptual e os conceitos de Domínio e Mapeamento para indicar como foram conceitualizados metaforicamente temas importantes do discurso.

Alguns trabalhos foram realizados tanto na perspectiva da Metáfora Conceptual quanto da Metáfora Discursiva em relação à esfera política. No âmbito da Metáfora Conceptual, Lakoff (2002) descreve as metáforas que permeiam o pensamento político norte-americano. Segundo o autor, os dois principais grupos político-filosóficos dos EUA, os chamados 'liberais' e os 'conservadores', sustentam-se sobre duas grandes metáforas distintas da família: os liberais apoiam-se na 'Nurturant Parent' (pais atenciosos, isto é, pai ou mãe que provê sustento e atenção) e 'Strict Father' (pai rigoroso). Essas duas metáforas servem como modelos de ação e pensamento e criam sistemas morais distintos, segundo o autor. No modelo Nurturant Parent a moralidade é conceitualizada metaforicamente como empatia, isto é, colocar-se no lugar de outra pessoa, sentir-se como ela e, assim, ajudar (e não prejudicar) essa pessoa, e por extensão, a comunidade em que ela vive. Algumas metáforas importantes desse sistema são A COMUNIDADE É UMA FAMÍlia, AGENTES MORAIS SÃO PAIS ATENCIOSOS, PESSOAS QUE PRECISAM DE AJUdA SÃO CRIANÇAS QUE PRECISAM DE ATENÇÃO e AÇÃO MORAL É PROVER ATENÇão E CUIDADO. Já no modelo Strict Father a noção de 'força moral' é central e é constituída por metáforas como SER BOM É SER ERETO (upright), SER RUIM É SER BAIXO, FAZER O MAL É CAIR, MORALIDADE É FORÇA, e O MAL É UMA FORÇA, entre outras. O modelo dos pais atenciosos corrobora políticas do Partido Democrata dos EUA, que é visto como de esquerda (no cenário político daquele país), tais como a defesa do meio ambiente, a criação de programas sociais de apoio aos mais carentes e até mesmo a legalização do aborto (quem precisa de aborto precisa de ajuda). Por sua vez, o modelo do pai rigoroso, segundo o autor, sustenta as políticas do Partido Republicano norte-americano, conservador, de direita, à medida que vê coerência em ações como a luta contra o terrorismo por meio de guerra armada, a redução do tamanho da máquina governamental e a redução dos impostos.

Ainda referente à Metáfora Conceptual, Lakoff (2004) apresenta princípios que, segundo ele, deveriam ser levados em conta pelos progressistas norte-americanos para reverter seus insucessos na política de seu país, como a derrota do Partido Democrata em duas eleições seguidas para a presidência, em 2000 e 2004, e nas eleições para o congresso durante 
esse mesmo período. Para o autor, uma das razões desses insucessos foi a falta de atenção às metáforas dos conservadores veiculadas pelo Partido Republicano. Por exemplo, um conceito chave no discurso conservador norte-americano durante os anos da presidência de George W. Bush foi o de 'rogue states' (países vilões), que era aplicado a países como o Irã e a Coreia do Norte. Esse conceito apoia-se na metáfora da NAÇÃO É UMA PESSOA, que também licencia expressões como 'países amigos' e 'países irmãos' e, por sua vez, desdobra-se na conceitualização de nações como sendo mais 'adultas', isto é, mais desenvolvidas ou industrializadas e nações 'infantis', as em desenvolvimento. Isso tem implicação para o entendimento do que seriam as Nações Unidas, que é constituída, na sua maioria, por países em desenvolvimento; sendo assim, esse organismo internacional pode ser entendido, pelos conversadores norte-americanos (que representam uma nação 'adulta'), como sendo uma organização que não merece muita atenção, visto que não atingiu a fase adulta. Ainda segundo o autor, ao negar um conceito explicitamente, tal conceito precisa ser, antes de mais nada, evocado mentalmente pelo ouvinte e torna-se ativo em sua mente; o fato de ter sido negado é de importância secundária. O conceito é ativado no enquadramento ('framing') vigente. Como lembra o autor, quando o ex-presidente Richard Nixon foi à TV, em discurso, dizer que não era um ladrão ('I'm not a crook'), na verdade evocou na mente dos telespectadores o conceito de 'ladrão' e não o de 'não ladrão' e reforçou a associação de sua imagem à de um malfeitor, pois esse era o enquadramento em voga naquele momento. Segundo essa linha de raciocínio, os progressistas não deveriam negar os conceitos explicitamente, como 'não acreditamos em nações vilãs', pois mesmo assim isso ainda traria à mente o enquadramento de nação vilã, que foi implantado pelo governo Bush.

Semino (2008) enfocou Metáforas Conceptuais presentes em pronunciamentos do ex-primeiro ministro britânico Tony Blair e do primeiro-ministro italiano Silvio Berlusconi. A autora não explicita necessariamente tais metáforas por completo, muitas vezes citando apenas o domínio fonte. A autora identificou metáforas da VIAGEM, que aparecem, por exemplo, no discurso de Blair na convenção de seu partido (Trabalhista), em que ele afirma que 'nunca fomos tão longe', referindo-se ao fato de o partido Trabalhista, sob sua liderança, ter sido re-eleito por seis vezes consecutivas. Em relação ao primeiro-ministro Berlusconi, a autora notou a presença maciça de metáforas de ESPORTE, Como o próprio nome de seu partido (Forza Italia), que é também o canto da torcida da seleção italiana de futebol. Além dessa, 
também observou metáforas do ESPORTE na maneira pela qual o primeiroministro descreve o cenário político de seu país como sendo um campo de futebol, em que as decisões políticas acontecem na grande área, onde o risco de pênalti é grande.

Mestriner (2009) também investigou o discurso político tanto do ponto de vista da Metáfora Conceptual quanto da Metáfora Discursiva. A autora buscou metáforas compartilhadas pelos presidentes George W. Bush e Luís Inácio Lula de Silva, em corpora formados por centenas de pronunciamentos de ambos. Com o apoio de ferramentas computacionais como o Identificador de Metáforas do CEPRIL, encontrou diversas metáforas linguísticas e conceptuais em comum no discurso dos dois presidentes. Por exemplo, tanto Bush quanto Lula usaram metáforas conceptuais como GOVERNAR É uma viagem e compreender é ver. Por outro lado, cada um deles usou Metáforas Discursivas distintas, como compreEnder o FUtUro É ver (Lula) e COMPREENDER UM PERIGO É VER (Bush).

No âmbito da Metáfora Discursiva, Cameron (2007) identificou metáforas empregadas por um ex-terrorista irlandês (Pat Magee) e uma cidadã inglesa (Jo Berry) durante sessões de conciliação. Magee havia detonado uma bomba, em nome do Exército Republicano Irlandês (IRA), que visava a matar a primeira ministra britânica, mas que levou à morte o pai de Berry, que na época servia no governo britânico. Os dois se encontraram vinte anos depois, a pedido de Berry, para conversarem a fim de que ela pudesse entender os motivos que levaram Magee a praticar aquele ato. Algumas das metáforas encontradas por Cameron foram LUTO É SEPARAÇão, que caracteriza o sentimento de solidão e desamparo sentido por Berry, quando ela diz que 'chorava no deserto'; COMPREENDER o OUTRO REQUER CONEXÃo, que se refere à necessidade sentida pelos interlocutores durante a conciliação de se aproximarem metaforicamente, por meio de expressões como 'construir pontes' e 'derrubar barreiras'; e RECONCILIAÇÃo É MUDAR A IMAGEM DISTORCIDA DO OUTRO, revelada por expressões como 'ver o cenário global da política' da época e 'enxergar o outro na luz correta' ('see each other in our true light').

\section{Linguística de Corpus}

A Linguística de Corpus é uma área que se ocupa da coleta e análise de corpora, ou conjuntos de dados linguísticos (textos e transcrições de 
fala) armazenados em arquivo de computador (Berber Sardinha, 2004). Recentemente, tem havido um interesse crescente em identificar metáforas em corpora (Deignan, 2005).

Há, entretanto, muitos desafios para o estudo de metáfora com corpora. Um deles diz respeito à necessidade do uso de programas de computador para processar corpora. O problema é que a metáfora é um recurso de significado, mas os programas de análise de corpora partem da identificação de formas linguísticas e não de seus significados. Sendo assim, os programas de que dispomos para manuseio de corpora são inadequados para identificação de metáforas.

A solução, no momento, é vasculhar os corpora a partir de determinadas formas (palavras) e depois analisar o resultado dessas buscas (concordâncias) por meio da leitura humana. A análise apresentada aqui segue esse princípio: primeiramente, foram levantados todos os itens de vocabulários de mais destaque na fala do presidente, e a seguir foi feita uma análise minuciosa e qualitativa de um desses itens (desenvolvimento).

Contudo, a investigação da metáfora na perspectiva da Linguística de Corpus permite avanços em ambos os campos. Para os estudos da metáfora, cria a possibilidade de identificar a regularidade do uso metafórico em larga escala. Além disso, faz com que o investigador enfoque usos reais e autênticos de metáfora, e não dados artificiais. Para a Linguística de Corpus, o estudo da metáfora oferece uma base cognitiva para o estudo do uso linguístico, tornando possível que sejam inferidos processos de pensamento a partir do emprego de vocabulário recorrente na fala e na escrita. Isso viria como resposta parcial a uma das grandes críticas à Linguística de Corpus é a de que ela tem sido pouco capaz de teorizar a respeito da linguagem em geral (cf. Thompson \& Hunston, 2006: 2).

Com base nesses pressupostos, realizamos a investigação em um corpus de pronunciamentos do presidente Lula para descobrir metáforas em uso de modo sistemático e abrangente. Esperamos com isso poder ir além daquelas metáforas comumente percebidas pela imprensa e pelo público em geral. O levantamento das metáforas conceptuais pode nos mostrar como o presidente conceitualiza aspectos importantes da vida nacional. Como as metáforas conceptuais são em grande parte usadas inconscientemente, nossa análise pode começar a mostrar como o presidente inconscientemente articula aspectos de seu governo. Devido à extensão do corpus e às limitações 
de espaço, não podemos oferecer aqui uma análise de todas as metáforas em uso pelo presidente.

\section{Metodologia}

Utilizamos os seguintes recursos na análise apresentada aqui:

Um corpus de pesquisa, composto por 868 pronunciamentos e discursos do presidente Luís Inácio Lula da Silva, coletados no site www.presidencia. gov.br, compreendendo a totalidade dos depoimentos disponíveis em fevereiro de 2006. O corpus possui 1.779.713 ocorrências ('tokens') e 32.757 formas ('types').

Uma lista de palavras de corpus de referência, da mesma língua do corpus de pesquisa, gravada no formato WordSmith Tools. Nos exemplos, empregamos o Banco de Português (Berber Sardinha, 2004), com 230.460.560 ocorrências ('tokens') e 607.392 formas ('types').

O programa WordSmith Tools (Scott, 1997) de análise de corpus; especificamente os componentes KeyWords, WordList e Concord.

\section{Análise de palavras-Chave do corpus}

Toda palavra de um corpus tem algum potencial de ser usada metaforicamente. Portanto, temos a princípio tantos Veículos quantos há formas ou vocábulos ('types') no corpus, ou seja, cerca de 33 mil. Claramente, precisamos de um mecanismo para fazer uma triagem inicial de palavras.

Para isso, usamos a ferramenta KeyWords para nos mostrar as palavras que mais características do corpus. Para retirar as palavras-chave, primeiramente fizemos uma lista do corpus e a salvamos. A seguir, fizemos uma outra lista de palavras do corpus de referência, o Banco de Português. Por fim, comparamos as duas com o programa KeyWords.

A figura abaixo mostra a tela do KeyWords com as palavras mais chave do corpus de pesquisa. 


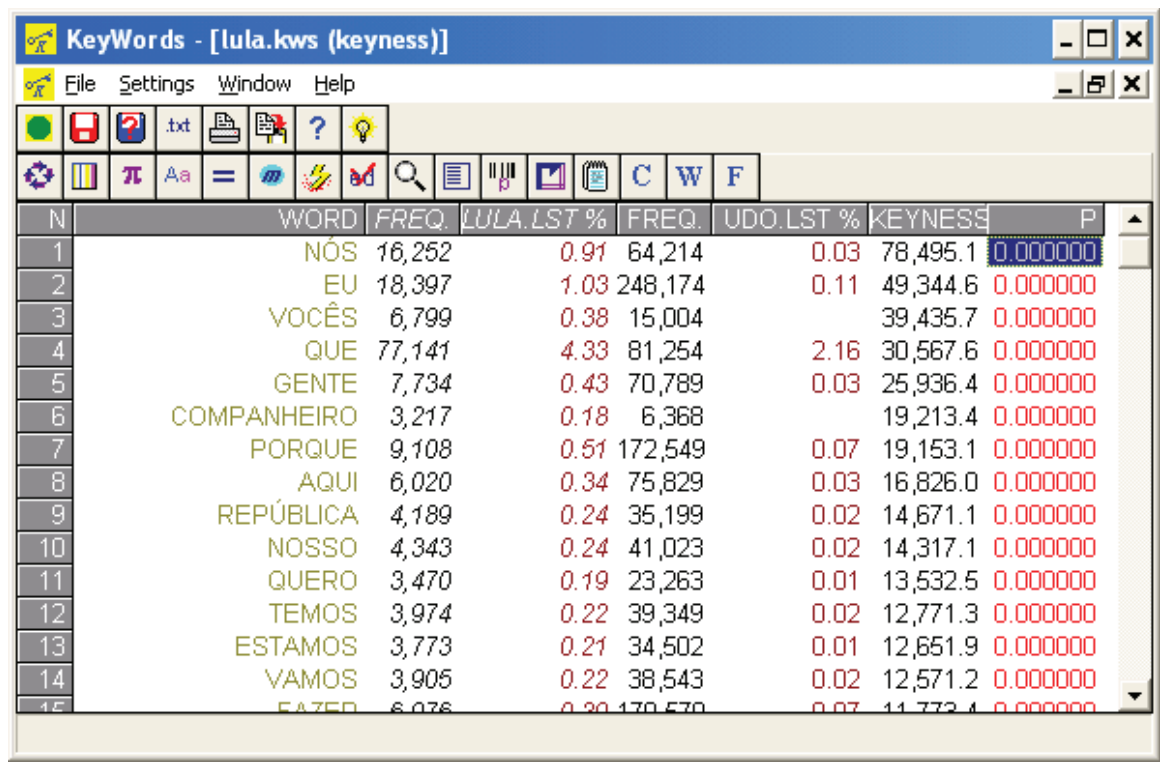

A lista está classificada por ordem de 'keyness', isto é, em ordem decrescente pelo valor da coluna 'Keyness'. Assim, a palavra 'mais chave' do corpus é 'nós', pois possui uma 'keyness' de 78495,1. Esse valor, por sua vez, representa a extensão da diferença de frequência de 'nós' nos dois corpora; no corpus de estudo, as ocorrências de 'nós' (16252) correspondem a $0,91 \%$ do total de ocorrências do corpus inteiro, ao passo que no corpus de referência, as ocorrências (64214) ocupam apenas $0,03 \%$ do corpus. A diferença entre os percentuais é muito grande (mais de 30 vezes), e é isso que o valor de Keyness reflete.

As palavras-chave principais do corpus refletem o caráter interativo da fala do presidente. Ele se remete aos seus interlocutores (nós, vocês, gente, companheiro) e a si mesmo (eu) com muita frequência. Outras características interativas do seu discurso são o uso das formas verbais da primeira pessoa do plural (temos, estamos, vamos), o emprego do pronome pessoal 'nosso' e a referência ao contexto imediato com o dêitico 'aqui'. Características como essas remetem a um discurso 'envolvido' (involved, segundo Biber, 1988), que engaja o interlocutor e pode fazer com que o presidente se aproxime de seus ouvintes. 


\section{ANÁLISE DE METÁFORA}

Para a análise de metáfora, é preciso olhar a lista de palavras-chave e ainda assim selecionar alguns candidatos a metáfora, ou seja, palavras que tenham certo potencial metafórico. Esse é um procedimento subjetivo, que depende da experiência do analista. Felizmente, há algumas classes de palavras que possuem maior probabilidade de uso metafórico (Berber Sardinha, 2008) e, portanto, o analista pode começar por elas:

adjetivos;

substantivos comuns;

verbos plenos.

Por verbos plenos, entendemos os verbos como 'cantar', 'correr', 'martelar', cujo sentido básico não depende de complemento. Em contrapartida, os chamados verbos 'deslexicalizados' possuem um sentido independente muito vago e por isso necessitam de complementação, como 'ter', 'dar' e 'tomar', por exemplo. Os verbos deslexicalizados são altamente metafóricos, principalmente porque se aliam a substantivos abstratos, resultando em metáforas ontológicas, como 'ter esperança', onde 'esperança' é metaforizada como algo concreto, possuível. Contudo, as metáforas resultantes desses verbos tendem a ser pouco reveladoras do discurso a ser analisado, já que usualmente são recursos da linguagem geral.

De modo similar, há a classe das preposições. Elas são usadas metaforicamente com muita frequência, porém seu uso metafórico é bastante geral (p.ex. 'ele está em apuros', onde 'em' é parte de uma metáfora de recipiente, em que 'apuros' são conceitualizados como receptáculos metafóricos) e pouco indicativo das especificidades do discurso contido no corpus de pesquisa.

Dessa forma, de volta à lista de palavras-chave, podemos seguir os seguintes passos:

Primeiramente, selecionar palavras-chave que sejam adjetivos, verbos plenos e substantivos comuns.

Em segundo lugar, fazer concordâncias de cada palavra. Caso a palavra possua muitas ocorrências, trabalhar com uma amostra delas. O ideal é usar cerca de mil instâncias de uma palavra (Deignan, 2005). Se a frequência for superior a mil, aplicar a opção 'at random', de Settings, e digitar um número que reduza o total de linhas para perto de mil. Por exemplo, se a 
frequência for 3.000, digitar 3, para que sejam retiradas 1.000 ocorrências (3000/3). Esse denominador somente pode ser um número inteiro. Portanto, se houver 2.367 ocorrências, é preciso usar 2 ou 3 para chegar próximo de $1.000(2.367 / 2=1.183,5 ; 2.367 / 3=789)$.

Em terceiro lugar, retirar os colocados das palavras e verificar quais parecem indicar metáforas.

Em quarto lugar, voltar à concordância e analisar cada linha dela, prestando atenção nos colocados promissores identificados na etapa anterior. Decidir se o uso da palavra é metafórico e codificar a concordância, de tal modo que cada uso metafórico seja sinalizado por um código (p.ex., 'm') na coluna 'Set' da concordância.

Em quinto lugar, elencar as metáforas linguísticas codificadas na concordância.

Por fim, nomear as metáforas conceptuais subjacentes a elas.

Seguindo esses procedimentos, o primeiro candidato a metáfora da lista de palavras-chave foi 'povo', na posição 24 da lista de palavras-chave:

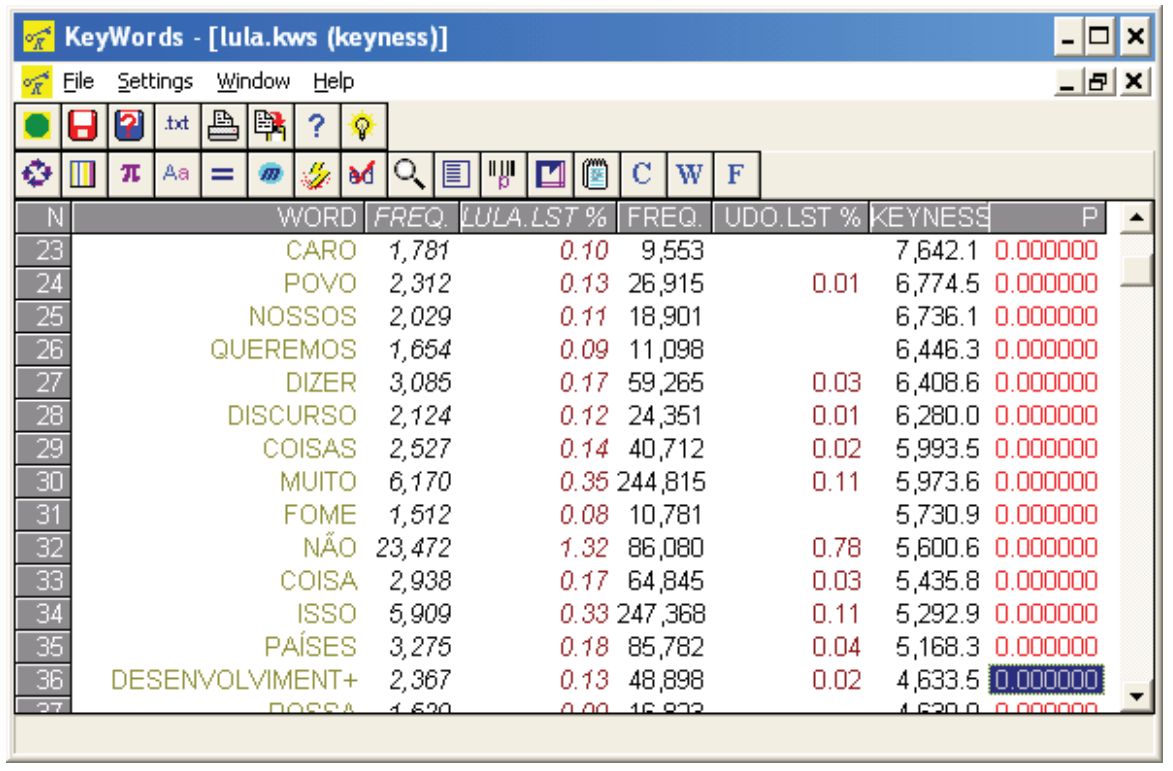


Fizemos a concordância de 'povo':

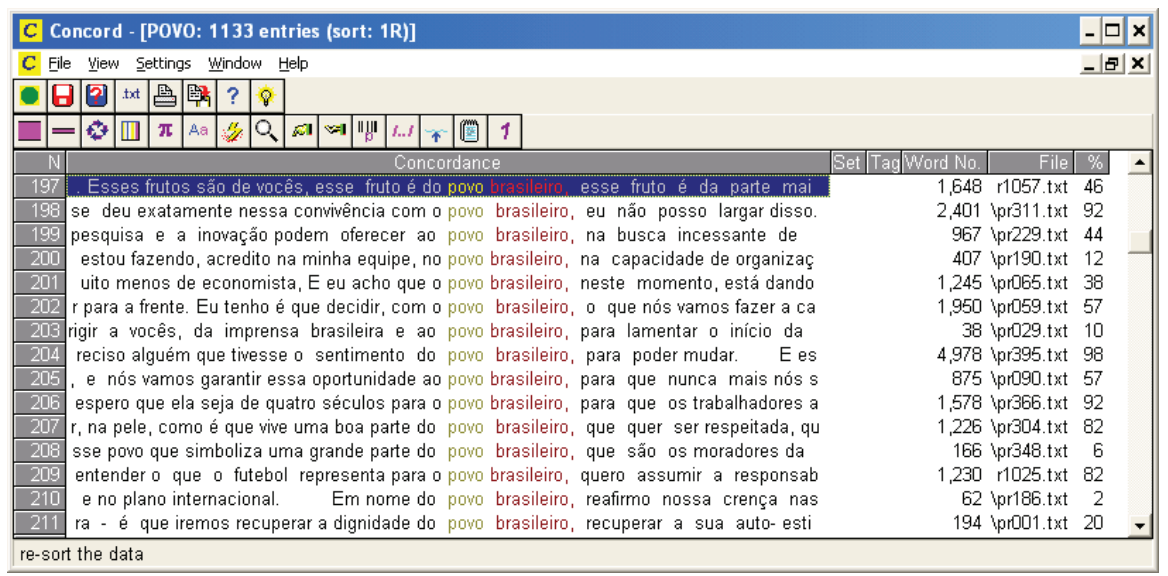

Analisamos a concordância e notamos que não havia nenhum uso metafórico.

Fizemos o mesmo com os próximos candidatos (dizer, discurso, coisas, fome, coisa, países e desenvolvimento).

\subsection{Metáforas de DeSEnvolvimento}

A palavra com maior potencial metafórico era 'desenvolvimento'. Fizemos a concordância dessa palavra e a seguir verificamos seus colocados. Aplicamos o denominador de redução 3, pois havia mais do que mil ocorrências (2.367), fazendo restar 789 linhas de concordância para analisar.

A seguir classificamos a concordância pela segunda palavra à esquerda (L2): 


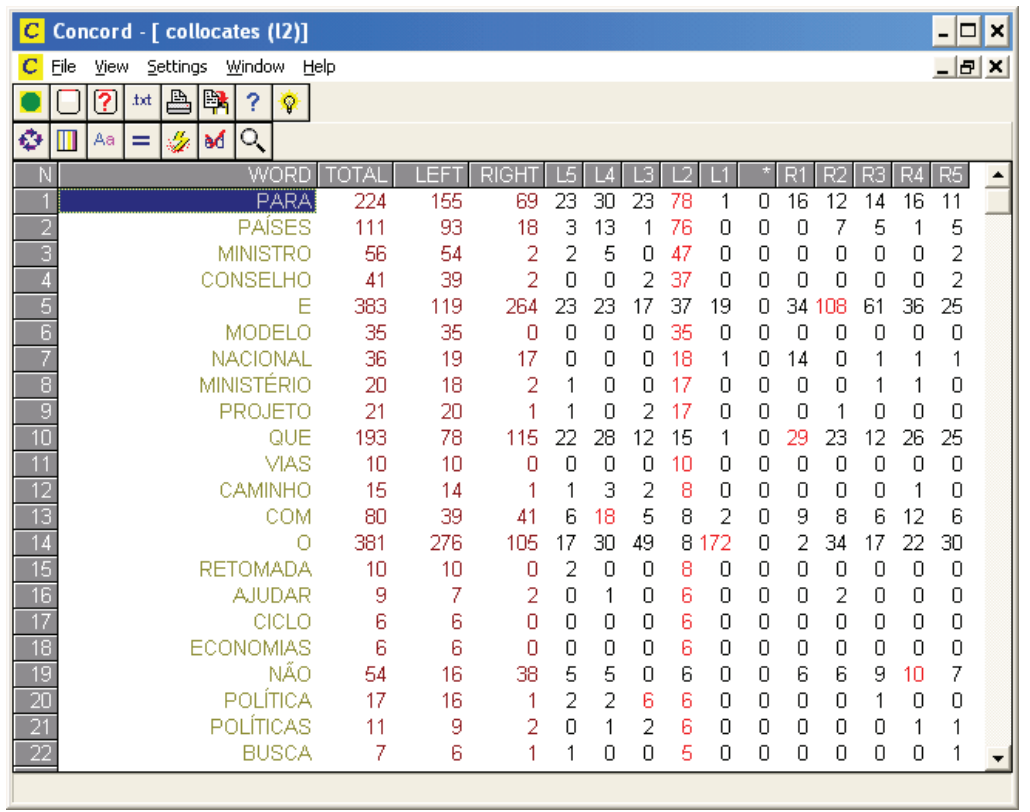

Novamente, o analista deve usar sua experiência e conhecimento para identificar possíveis Veículos na lista de colocados. Entre os colocados, os seguintes parecem promissores, juntamente com os campos fonte que parecem indicar:

\begin{tabular}{|l|l|}
\hline Colocado & Campo fonte possível \\
\hline Modelo & Construção \\
\hline Projeto & Construção \\
\hline Vias & Viagem \\
\hline Caminho & Viagem \\
\hline Retomada & Viagem \\
\hline Ciclo & Organismo \\
\hline Busca & Viagem \\
\hline
\end{tabular}

A nomeação dos campos fontes foi feita segundo a prática aceita nos estudos de metáfora. Os analistas de metáfora se servem de dicionários, ontologias e da literatura prévia para designar os campos. Tal prática está longe de ser satisfatória, pois significa que pode haver muita discrepância entre os campos indicados por analistas diferentes, ou até por um mesmo analista em épocas diferentes. Não há, contudo, ferramentas específicas para 
auxiliar nesse processo, nem maneiras de obter os campos automaticamente por análise de corpus.

Para cada um dos colocados, foi preciso voltar à concordância e analisála. Anotamos os usos metafóricos com o código 'm' na coluna 'Set' da concordância:

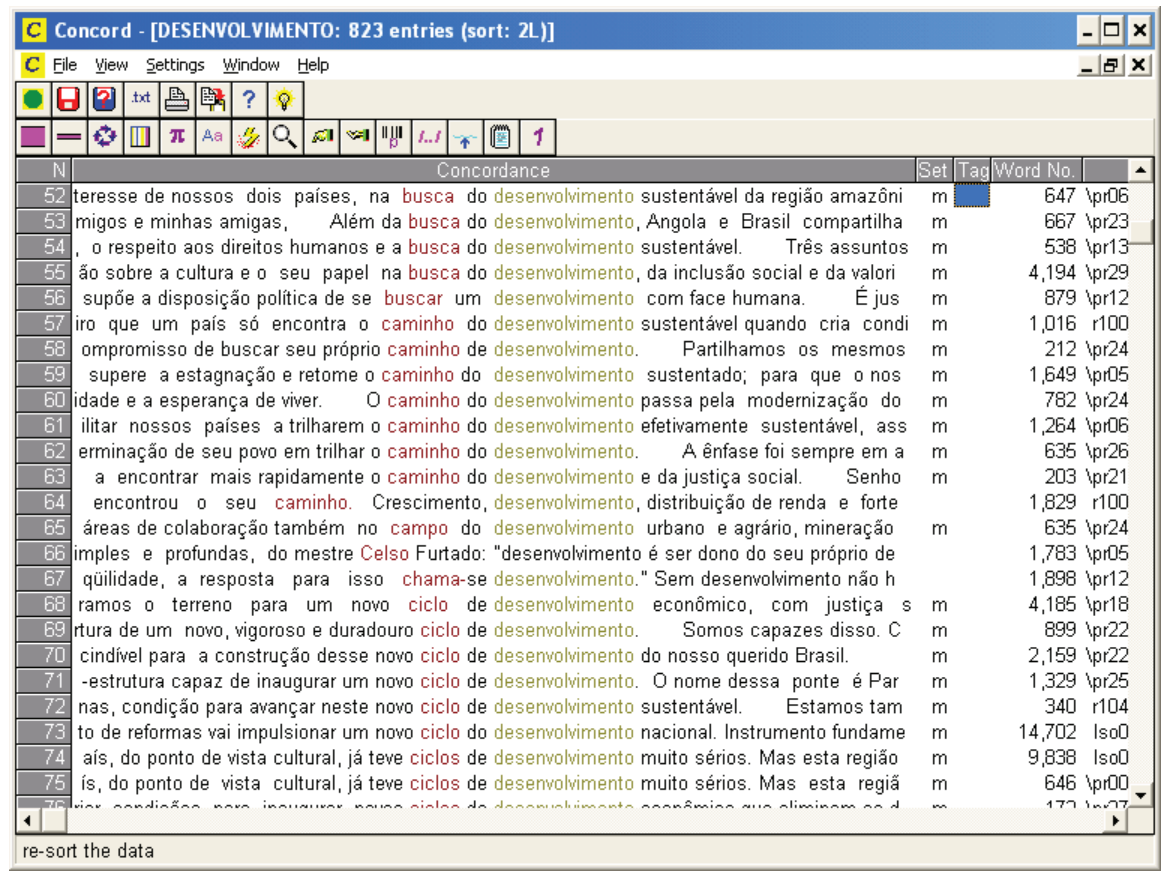

Quando reconsideramos a análise de uma linha, digitamos um outro código em lugar do 'm', pois não é possível apagar um código já digitado na coluna 'Set'. Escolhemos digitar ' $z$ ' nesses casos:

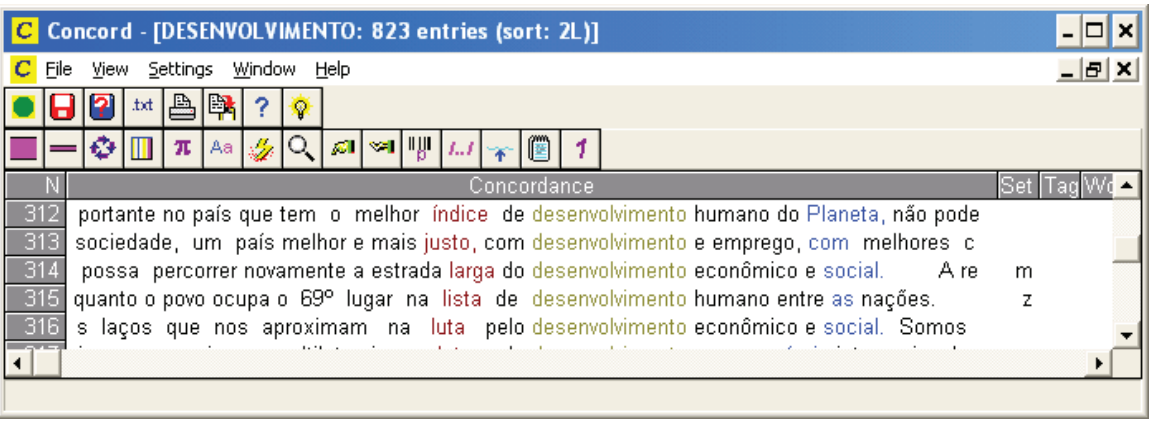


Reclassificamos a concordância pela segunda palavra à esquerda (2L) e isso nos ajudou a verificar os usos potencialmente metafóricos. Não há regra sobre qual coluna deva ser a de classificação, por isso o analista deve experimentar várias. Uma mesma concordância pode ser reclassificada de vários modos para permitir a visualização dos padrões.

Ao final da análise da concordância, fizemos uma reclassificação pela coluna 'Set'. Tivemos o cuidado de fazer uma segunda classificação pela posição 2L (para mantermos a concordância ordenada conforme a usamos na análise) e selecionar a opção 'Ascending' (para que as linhas com 'm' fossem todas deslocadas para o topo da lista):

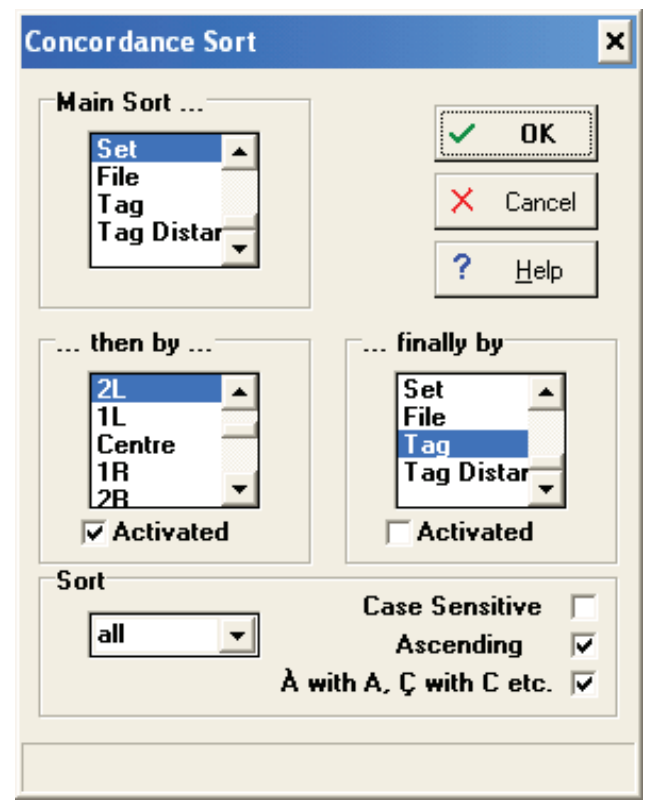


Como resultado, obtivemos a concordância a seguir:

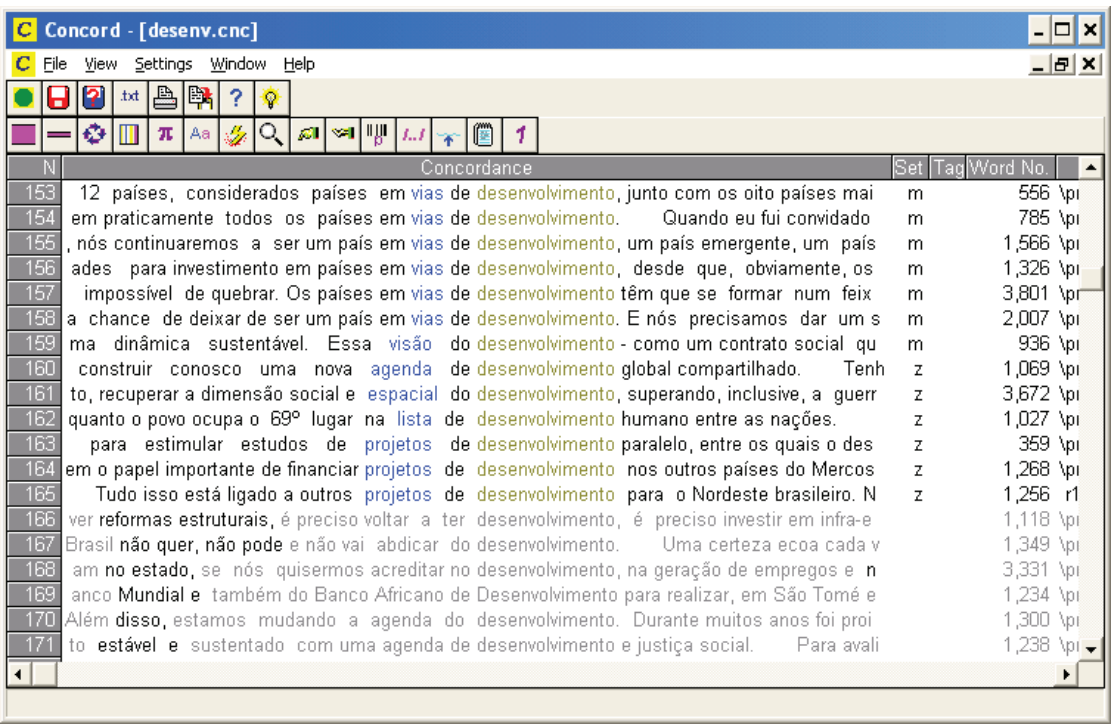

As linhas que não possuem código (os usos não metafóricos) tornam-se cinza. As linhas com o código ' $z$ ' (os casos reconsiderados que passaram de metafóricos para não metafóricos) continuam em cor preta.

Com essa classificação, pudemos facilmente contar quantos usos metafóricos havia: 159 (é o número da linha onde aparece o último 'm' na coluna 'Set'). A probabilidade de uso metafórico de 'desenvolvimento' pode ser calculada assim:

$$
159 / 789=0,201
$$

Multiplicando por 100, obtemos a porcentagem de uso metafórico: $20 \%$.

A seguir, elencamos as metáforas linguísticas que codificamos e nomeamos as metáforas conceptuais (em ordem alfabética):

1. Acelera o desenvolvimento (DESENVOLVIMENTO É UMA MÁQUINA)

2. Avenida de desenvolvimento (Desenvolvimento é Viagem)

3. Caminho do desenvolvimento (DESENVOLVIMENTo É VIAGEM) 
4. Ciclo de desenvolvimento (DESENVOLVIMENTO É UM ORGANiSMO)

5. Com vistas a um desenvolvimento (DESENVOLVIMENTO É UM OBJETO)

6. Dimensão espacial do desenvolvimento (Desenvolvimento É UM OBJETO)

7. Em vias de desenvolvimento (DESENVOLVIMENTO É VIAGEM)

8. Entrave ao desenvolvimento (DESENVOLVIMENTO É VIAGEM)

9. Estimular o desenvolvimento (DESENVOLVIMENTO É UM ORGANISMO)

10. Estrada larga do desenvolvimento (DESENVOLVIMENTo É Viagem)

11. Estratégia de desenvolvimento (DESENVOLVIMENTo É GUERRA)

12. Etapa do desenvolvimento (DESENVOlVIMENTo É VIAGEM)

13. Gargalos do desenvolvimento (DESEnVOLVIMENTO É UMA GARRAFA)

14. Geração de desenvolvimento (desenvolvimento é um organismo)

15. Luta pelo desenvolvimento (DESENVOLVIMENTO É GUERRA)

16. Mar aberto do desenvolvimento (DESENVOLVIMENTO É O MAR)

17. Modelo de desenvolvimento (Desenvolvimento É Uma CONSTRUÇão)

18. Níveis de desenvolvimento (DESENVOLVIMENTo É UM RECIPIENTE)

19. Padrão de desenvolvimento (Desenvolvimento é um OBJeto)

20. Paradigma de desenvolvimento (DesenvolviMENTo é UMA CIÊNCIA)

21. Passar pelo desenvolvimento (Desenvolvimento é Viagem)

22. Perspectivas de desenvolvimento (Desenvolvimento É uma CONSTRUÇÃO)

23. Pilar do desenvolvimento (Desenvolvimento é uma CONSTRUÇÃo)

24. Plano de desenvolvimento (Desenvolvimento é uma ConstruÇão)

25. Projeto de desenvolvimento (Desenvolvimento É Uma CONSTRUÇão)

26. Retomada do desenvolvimento (DESENVOLVIMENTO É VIAGEM)

27. Rota do desenvolvimento (DESENVOLVIMENTO É VIAGEM)

28. Rumos do desenvolvimento (DESENVOLVIMENTO É VIAGEM)

29. Trava o desenvolvimento (DESENVOLVIMENTO É UMA MÁQUina)

A análise indica que o presidente Lula metaforizou desenvolvimento principalmente como viagem (dez metáforas conceptuais), construção (cinco), objeto (três) e organismo (três). A seguir exemplificamos os principais usos metafóricos associados a essas metáforas conceptuais. 
Primeiramente, o presidente usa as metáforas linguísticas do 'caminho' e da 'rota' do desenvolvimento, para significar que o desenvolvimento é um percurso longo, que precisa ser encontrado e trilhado. Ele qualifica o percurso algumas vezes como sendo 'sustentável', ou seja, que possa ser mantido por um certo período de tempo.

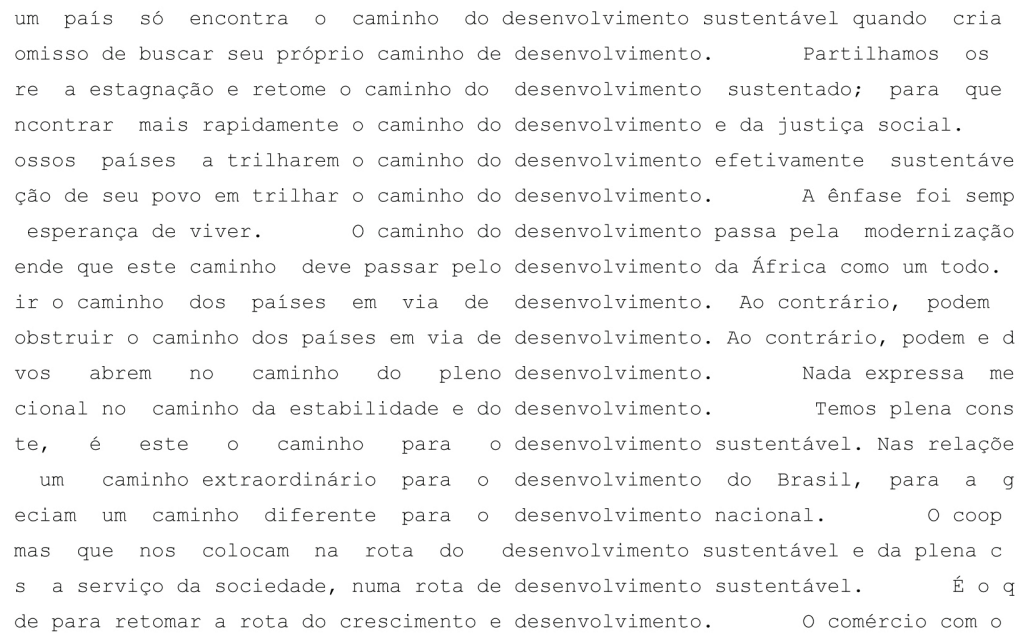

O caminho sustentado ou sustentável é um percurso difícil, que pode apresentar obstáculos, ou 'entraves':

eio ambiente não seja um entrave ao desenvolvimento sustentável deste país ca de superar os principais entraves ao desenvolvimento sustentado do país. E ac

O presidente ainda emprega a metáfora linguística dos 'rumos do desenvolvimento', que parecem indicar uma direção mais incerta do que o 'caminho' ou a 'rota do desenvolvimento'. Os rumos precisam ser debatidos, para que possam ser orientados:

esentaram para debater os rumos do desenvolvimento do Brasil. Isso renova a onsabilidade pública sobre os rumos do desenvolvimento nacional. Isso signifi dade para orientar os rumos do nosso desenvolvimento e decidir o futuro da 
Esse percurso do desenvolvimento não é algo novo, conforme indica a metáfora linguística da 'retomada do desenvolvimento'. O país já foi um viajante nesse caminho, mas sai dele e precisa voltar a trilhá-lo. Essa retomada não é uma tarefa simples, pois requer 'superação' e algumas 'condições necessárias':

a retomada de um verdadeiro projeto de desenvolvimento nacional e republicano.

de estabilidade e retomada do desenvolvimento do país. Sabemos que a

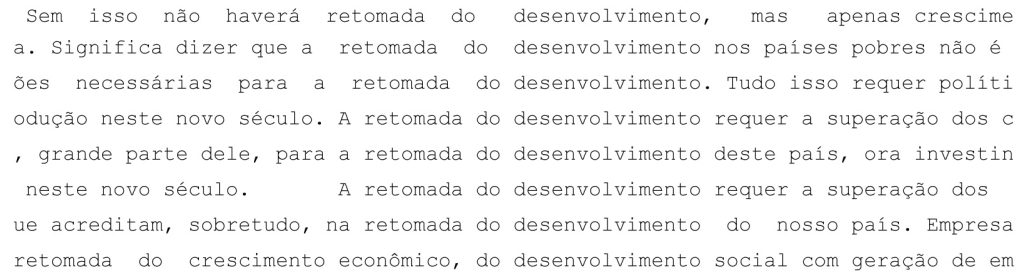

Há ainda uma ocorrência de 'avenida do desenvolvimento': "vamos lutar para que o comércio e os fluxos de investimentos internacionais transformemse em verdadeira avenida de desenvolvimento. Para isso é necessário que seja uma via de mão dupla" (Pronunciamento de 24/3/2003, em Cusco, Peru).

É interessante o uso de 'verdadeira' para enfatizar a metáfora. Esse é um tipo de 'mecanismo de sintonia' ('tuning device' Cameron \& Deignan, 2003), uma classe de expressões cuja função é ajustar a força de expressões metafóricas às intenções do falante e às expectativas do ouvinte. No exemplo em questão, 'verdadeiro' serve para reforçar 'o sentido de uma metáfora que [o falante] pode ter julgado ser tão velha que, se não o fizesse, passaria despercebido ${ }^{1}$ ' (Cameron \& Deignan, 2003: 155). 'Mão dupla', logo a seguir, serve para especificar o tipo de avenida.

Em segundo lugar, o presidente faz uso da metáfora da construção, para significar que o desenvolvimento precisa ser planejado conscientemente. As citações abaixo, de 'pilar' e 'projeto', exemplificam esse uso:

1. No original: "the meaning of a metaphor that he or she may have judged to be so well-worn that it will otherwise be missed". 
ue nós pensamos em um grande plano de desenvolvimento, precisamos pensar també ê? Porque, afinal de contas, o plano de desenvolvimento para um país não pode feito o melhor plano possivel para o desenvolvimento do turismo nesta reg

\begin{abstract}
as bases de nosso projeto de desenvolvimento. Assim, nasceu a Petról que inviabilizava qualquer projeto de desenvolvimento de longo prazo e penal zemos uma discussão de um projeto de desenvolvimento do país envolvendo toda be da mão da sociedade um projeto de desenvolvimento para o Brasil, visitar tica industrial claro e um projeto de desenvolvimento para o país, tudo f a retomada de um verdadeiro projeto de desenvolvimento nacional e republicano. e engajar amplos setores num projeto de desenvolvimento com base na justiça s os, carente de um verdadeiro projeto de desenvolvimento nacional e de um planeja - Brasil pode e deve ter um projeto de desenvolvimento que seja ao mesmo tempo e engajar amplos setores num projeto de desenvolvimento com base na justiça s cidades, nós apresentamos um projeto de desenvolvimento para o vale do Jequitinh possa, ao elaborar um outro projeto de desenvolvimento, ter clareza de que este go mesmo, vale dizer, com um projeto de desenvolvimento que tenha no povo o sso está ligado a outros projetos de desenvolvimento para o Nordeste brasil eção de projetos conjuntos de pesquisa, desenvolvimento e transferência tecnol cil construir um projeto democrático de desenvolvimento nacional. A Previdência as também de projetos voltados para o desenvolvimento de infra-estrutura fí vançarmos juntos em nossos projetos de desenvolvimento nacionais e regionais. rias, que elaboram grandes projetos de desenvolvimento nacional e regionais. E, onstrução de um projeto republicano de desenvolvimento social e econômico. Um p
\end{abstract}

Algumas vezes, os elementos da construção são especificados, como é o caso da agricultura, chamada de um dos 'pilares' do desenvolvimento:

agricultura não era mais um pilar do desenvolvimento nacional. Houve um tempo agricultura ainda é um dos pilares do desenvolvimento do país, hoje, mais do q

Por fim, o presidente evoca metáforas do organismo, tratando o desenvolvimento como algo que possui vida própria. Uma metáfora linguística associada a esse conceito metafórico é a do 'ciclo do desenvolvimento', que indica um período de 'vida' e que pode ser 'vigoroso', 'duradouro':

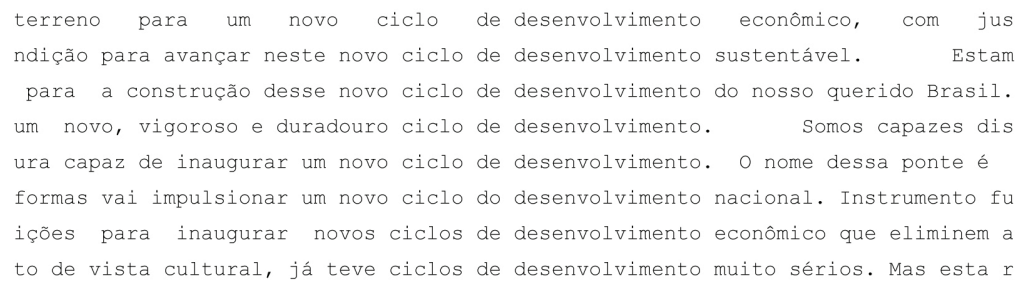


Ainda segundo a metáfora do organismo, o desenvolvimento pode ser 'gerado', ganhando vida:

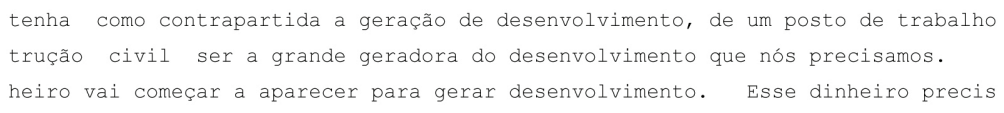

O desenvolvimento ainda pode ser estimulado:

\subsection{INTERPRETAÇÃO}

A quantidade expressiva de metáforas usadas em relação a desenvolvimento (20\%) não é surpreendente, por três razões. Em primeiro lugar, desenvolvimento é um conceito abstrato, o que requer mapeamentos metafóricos com conceitos concretos para ser entendido (Lakoff \& Johnson, 1980).

Em segundo lugar, trata-se de um conceito indeterminado, que precisa ser especificado; desse modo, as metáforas ajudam a tornar mais claro o sentido desejado. Conforme explica Arndt (1987: 1):

Qualquer um que pergunte a cidadãos articulados de países desenvolvidos o que eles querem dizer com esse objetivo desejado do 'desenvolvimento' receberia uma grande variedade de respostas. Padrões de vida mais altos. Uma renda per capita crescente. Aumento da capacidade produtiva. (...) O desenvolvimento, na vasta literatura sobre o assunto, parece ter vindo para englobar todas as facetas da boa sociedade, a estrada para a utopia do homem comum. ${ }^{2}$

Em terceiro lugar, o presidente precisa comunicar-se com o público em geral, e as metáforas são instrumentos extremamente úteis para aproximar o político das massas:

2. No original: "anyone who asked articulate citizens in developed countries what they meant by this desirable objective of 'development' would get a great variety of answers. Higher living standards. A rising per capita income. Increase in productive capacity. (...) Development, in the vast literature on the subject, appears to have come to encompass almost all facets of the good society, everyman's road to utopia". 
(...) A escolha da linguagem em geral e das metáforas em particular é essencial para o poder de persuasão geral [de um líder político]. A identificação das bases cognitivas e afetivas da metáfora pode explicar por que ela é necessária para uma liderança de sucesso. (...) A metáfora é sistematicamente relacionada a outras estratégias linguísticas (...) e é central para a criação de sistemas de crenças persuasivos ${ }^{3}$ (Charteris-Black, 2005: 2).

As três metáforas conceptuais discutidas acima mostram o desenvolvimento como um percurso longo, que deve ser construído segundo um plano previamente definido; ao mesmo tempo, o desenvolvimento é um ser vivo, que é gerado e estimulado a crescer. Aparentemente, há uma contradição nesse conjunto metafórico, pois de um lado temos o desenvolvimento como objeto inanimado, e de outro, como animado.

Esse conflito é resolvido na medida em que o discurso do presidente aponta os agentes que dão vida ao desenvolvimento, que é o próprio governo: "e nós temos consciência de que, levando as universidades para o interior, a gente vai gerar desenvolvimento nas cidades pobres do nosso país" (Pronunciamento de 20/10/2005, no $11^{\circ}$ Congresso Nacional do PC do B, em Brasília-DF).

E, ainda:

Imaginem vocês o que significa, para essa região, quando essa universidade estiver pronta aqui, com 2.500 alunos, com cientistas, com professores, com funcionários, com pesquisadores. Imaginem o que vai gerar de desenvolvimento nesta região, imaginem o que vai ajudar no desenvolvimento (Pronunciamento de 3/8/2005, em Guaranhuns-PE).

Dessa maneira, em ambos os casos o desenvolvimento é tido como algo levado a cabo pelo governo.

Assim, a noção de desenvolvimento evocada pelo presidente embute três conceitos principais:

3. No original: “(...) Choice of language in general and metaphor in particular is essential to [political leaders'] overall persuasiveness. Identification of the cognitive and affective basis of metaphor can explain why it is necessary for successful leadership. (...) Metaphor is systematically related to other linguistic strategies and (...) it is central to the creation of persuasive belief systems'. 
1. Deslocamento em uma viagem;

2. Planejamento de um edifício;

3. Geração de um ser vivo.

Esses três conceitos, por sua vez, são atrelados à ação do governo, que, dessa maneira, assume três papéis metafóricos:

1. Motorista ou piloto (na viagem);

2. Engenheiro ou arquiteto (na construção);

3. Pai ou mãe (na geração do ser vivo).

As metáforas empregadas pelo presidente para conceitualizar desenvolvimento são bastante convencionais no âmbito político. Charteris-Black (2005) notou a presença de metáforas de viagem, construção e organismo na retórica de políticos contemporâneos. Segundo ele, a viagem é um campo fonte que serve para entender muitos conceitos políticos e sociais. A metáfora geral nesses casos é ATIVIDADES DE LONGO PRAZO COM UM INTUITO SÃO VIAGENS ${ }^{4}$ (Charteris-Black, 2005: 152).

\section{Comentários Finais}

Neste trabalho, mostramos metáforas usadas pelo presidente Luís Inácio Lula da Silva para se referir a 'desenvolvimento'. O uso abundante de metáforas se tornou uma marca registrada da retórica do presidente, mas, normalmente, as reportagens sobre o assunto deixam evidente apenas as metáforas mais deliberadas, como as do futebol. Nossa intenção foi de ir além dessas metáforas explícitas e buscar outras menos perceptíveis, porém de alta ocorrência e que, por conseguinte, mostram como o presidente entende certos temas importantes da vida nacional.

A metodologia adotada na pesquisa aliou as perspectivas da Metáfora Discursiva e da Metáfora Conceptual, pois, de um lado, partiu do exame sistemático das metáforas linguísticas (assim alinhando-se com uma visão discursiva) e, de outro, buscou os domínios relativamente amplos de conhecimento mobilizados pelas metáforas como expressões do pensamento do presidente (aproximando-se de uma visão conceptual da metáfora).

4. "Long-term purposeful activities are journeys". 
A metodologia foi ascendente, no sentido de que partiu dos dados disponíveis em um grande corpus de falas do presidente, sem uma lista de metáforas pré-identificadas para servir de ponto de partida. A pesquisa foi viabilizada por meio das ferramentas do programa WordSmith Tools, que nos ofereceram maneiras de fazer uma triagem de palavras com potencial metafórico, via levantamento de palavras-chave.

Nossa análise deteve-se nos usos da palavra 'desenvolvimento', que é marcadamente metafórica no discurso presidencial. A análise também revelou vários conceitos embutidos na concepção de desenvolvimento que o presidente expõe nos seus discursos. A análise deixou claro que há uso sistemático de três conceitos metafóricos que definem a noção de desenvolvimento do chefe de Estado: VIAGEM, CONSTRUÇão E ORGANISMO. Esses três conceitos, em geral, equacionam desenvolvimento com um processo longo, construído, planejado e gerado pelo governo e são veiculados em um discurso de características marcadamente interacionais (como revelaram as principais palavras-chave do corpus).

Uma limitação deste trabalho é que não pudemos determinar se o presidente utiliza as metáforas do desenvolvimento mais frequentemente do que outros políticos ou outros cidadãos brasileiros. Talvez essa metáfora seja muito comum no discurso político em geral e não seja uma característica marcante apenas no discurso de Lula.

Desenvolvimento esteve na agenda governamental desde a Segunda Guerra Mundial. Por isso, não é surpreendente que tenha sido palavra-chave das falas oficiais do presidente da República. Desenvolvimento também é um conceito abstrato e indeterminado. Isso faz com que seja por natureza metafórico.

Entretanto, como desenvolvimento não é o único conceito com essas características, é interessante que tenha tido tanta proeminência no discurso do presidente, cuja plataforma política centrou-se mais em políticas sociais de distribuição de renda do que de desenvolvimento econômico.

A visão de desenvolvimento do presidente não é original. Ela tem estado presente na retórica política há pelos menos meio século, desde o pós-guerra. Talvez até por isso esse seu uso de metáforas passe despercebido.

Esperamos que este trabalho acenda o interesse de outros pesquisadores em levantar outras metáforas sistemáticas no discurso político brasileiro, 
ajudando, assim, que conceitos centrais para a vida nacional sejam explicitados.

Recebido em março de 2008 Aprovado em outubro de 2008

E-mail: tony@corpuslg.org

\section{REFERÊNCIAS BIBLIOGRÁFICAS}

Arndt, H. W. 1987. Economic Development: The History of an Idea. Chicago: University of Chicago Press.

Berber Sardinha, T. 2004. Linguística de Corpus. São Paulo: Manole. . 2007. Metáfora. Sao Paulo: Parábola.

2008. Metaphor probabilities in corpora. In: ZanotTo, M. S.; Cameron, L.; Cavalcanti, M.. (Eds.). Confronting Metaphor in Use: An Applied Linguistic Approach. Amsterdam/Atlanta, GA: Benjamins, p. 127-148.

(Ed.). 2005. A lingua portuguesa no computador. Campinas: Mercado de Letras/FAPESP.

Biber, D. 1988. Variation Across Speech and Writing. Cambridge: Cambridge University Press.

Cameron, L. 2003. Metaphor in Educational Discourse. London: Continuum.

. 2007. Patterns of metaphor use in reconciliation talk. Discourse and Society, 18(2):197-222.

Cameron, L.; Deignan, A.. 2003. Combining large and small corpora to investigate tuning devices around metaphor in spoken discourse. Metaphor and Symbol, 18(3):149-160.

Charteris-Black, J. 2004. Corpus Approaches to Critical Metaphor Analysis. Basingstoke: Palgrave Macmillan.

. 2005. Politicians and Rhetoric: The Persuasive Power of Metaphor. Basingstoke: Palgrave Macmillan.

Deignan, A. 2005. Metaphor and Corpus Linguistics. Amsterdam/Philadelphia: John Benjamins.

Lakoff, G. 2002. Moral Politics: How Liberals and Conservatives Think. 2. ed. Chicago: University of Chicago Press. 
.2004. Don't Think of an Elephant! Know Your Values and Frame the Debate: The Essential Guide for Progressives. White River Junction: Chelsea Green.

Lakoff, G.; Johnson, M.. 1980. Metaphors We Live By. Chicago: University of Chicago Press.

Mestriner, V. 2009. Metáforas de Luís Inácio Lula da Silva e de George W. Bush numa perspectiva da Linguística de Corpus. Dissertação de Mestrado. São Paulo: PUC-SP.

Scott, M. 1997. WordSmith Tools, version 3. Programa de computador. Oxford: Oxford University Press.

Semino, E. 2008. Metaphor in Discourse. Cambridge: Cambridge University Press.

Thompson, G.; Hunston, S.. 2006. System and corpus: Two traditions with a common ground. In: System and Corpus. London: Equinox, p. 1-14. 